\title{
Effect of a Chloroacetyl Modification on the Suppression of Dissociation of a Fluorescent Molecule from Cells for Antigen-Specific Cell Staining
}

\author{
Ryosuke Kaneko, ${ }^{* 1}$ Masumi Kawamura, ${ }^{* 2}$ Akihiro Kishimura, ${ }^{* 1, * 2, * 3, * 4}$ Takeshi MorI, ${ }^{* 1, * 2, * 3 \dagger}$ and \\ Yoshiki KATAYAMA $* 1, * 2, * 3, * 4, * 5, * 6 \dagger$ \\ *1 Department of Applied Chemistry, Faculty of Engineering, Kyushu University, 744 Motooka, Nishi, \\ Fukuoka 819-0395, Japan \\ *2 Graduate School of System Life Science, Kyushu University, 744 Motooka, Nishi, Fukuoka 819-0395, Japan \\ *3 Center for Future Chemistry, Kyushu University, 744 Motooka, Nishi, Fukuoka 819-0395, Japan \\ *4 International Research Center for Molecular Systems, Kyushu University, 744 Motooka, Nishi, \\ Fukuoka 819-0395, Japan \\ *5 Center for Advanced Medical Innovation, Kyushu University, 3-1-1 Maidashi, Higashi, Fukuoka 812-8582, \\ Japan \\ *6 Department of Biomedical Engineering, Chung Yuan Christian University, 200 Chung Pei Rd., Chung Li, \\ 32023 ROC, Taiwan
}

\begin{abstract}
We previously developed a hydrolase-based fluorescence amplification method for antigen-specific cell labelling, in which fluorescent substrates stained cells by a non-covalent hydrophobic interaction. To improve the substrates retention in cells, we examined the effect of a chloroacetyl group modification on the substrate retention. We found that the chloroacetyl group suppressed the dissociation of the substrate after forming a covalent bond with intracellular proteins. However, the slow reaction speed of the chloroacetyl group allowed dissociation for cells in the early stage of the staining reaction.
\end{abstract}

Keywords Antigen, antibody, fluorescence, enzyme, amplification

(Received October 10, 2020; Accepted December 17, 2020; Advance Publication Released Online by J-STAGE December 25, 2020)

\section{Introduction}

Cells are identified based on kinds and copy numbers of expressing membrane proteins. To label the membrane proteins, fluorophore-modified antibodies have been used. In this case, the autofluorescence of cells resulting from intracellular molecules determine the limit of detection of the copy numbers of membrane proteins, which is sometimes not satisfactory, especially when a fluorophore with a shorter wavelength is used. ${ }^{1,2}$ To improve the limit of detection, an enzymatic reaction of horse radish peroxidase has been utilized to accumulate a large number of fluorophores modified with enzymatic substrate domains. ${ }^{3-5}$

We previously extended the enzyme-based fluorescence signal amplification method to hydrolases, such as alkaline phosphatase and $\beta$-galactosidase (CARP method). ${ }^{6,7}$ The CARP method is based on the increment of hydrophobicity of the fluorescence substrate upon the removal of a hydrophilic group by enzymatic hydrolysis. The hydrophobic fluorescent substrate stained cells by a non-covalent hydrophobic interaction. Although the stability of the hydrophobic interaction is relatively strong,

$\dagger$ To whom correspondence should be addressed.

E-mail: mori.takeshi.880@m.kyushu-u.ac.jp (T. M.); ykatatcm@ mail.cstm.kyushu-u.ac.jp (Y. K.). dissociation of the fluorescent substrate is inevitable during long-time incubation.

Covalent bond formation with cellular components is generally used to avoid the dissociation of dyes in the fluorescent staining of cells. Reactive groups with thiol and amine groups in intracellular proteins have been utilized so far. ${ }^{8,9}$ Among these groups, we employed a chloroacetyl group, ${ }^{10}$ which has a good balance of stability and reactivity, i.e., being stable to afford the diffusion of dyes into cells, and reactive to rapidly form covalent bond with a thiol group. We examined the effect of the chloroacetyl group on suppressing the dissociation of a fluorescent substrate (Fig. 1).

\section{Experimental}

\section{Reagents and chemicals}

NovaSyn TGR resin was purchased from Novabiochem (Darmstadt, Germany). Dichloromethane (DCM) and trifluoro acetic acid (TFA) were obtained from Watanabe Chemical Industries (Hiroshima, Japan). N,N-Dimethylformamide (DMF) was obtained from Kanto Chemical (Tokyo, Japan). Chloroacetyl chloride and triisopropylsilane (TIS) were obtained from Tokyo Chemical Industry (Tokyo, Japan). Dimethyl sulfoxide (DMSO) was obtained from Wako Pure Chemical Industries (Osaka, Japan). Methyl- $\beta$-cyclodextrin (M- $\beta$-CD) was obtained from 


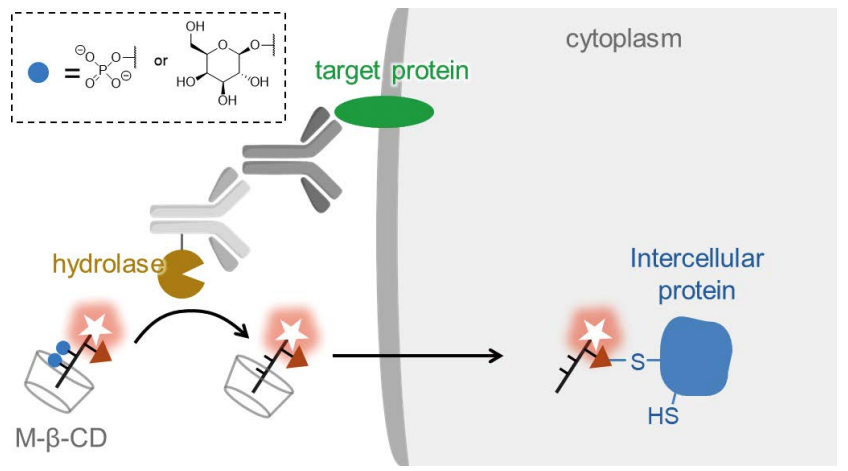

Fig. 1 Schematic illustration of cell staining by a fluorescent substrate with a thiol reactive group for the CARP method.

Sigma Aldrich (St. Louis, MO). NHS-rhodamine (TAMRA SE) and streptavidin protein were obtained from Thermo Fisher Scientific (Waltham, MA).

\section{Synthesis of 2}

Substrate 2 was synthesized on NovaSyn TGR resin using Fmoc compounds following the reported procedure ${ }^{11}$ with some modification. For introducting a chloroacetyl group and rhodamine onto each lysine residue, Mtt and ivDde protected lysines have been used, respectively. After synthesizing the main chain of the substrate on the resin, the ivDde group of the second lysine residue was removed by a deprotecting reagent (hydrazine:DMF = 2:98). Then, a DMF/0.1 M $\mathrm{NaHCO}_{3}$ (pH 8.3 - 8.5) (1/1) solution containing 1.5 equivalents of TAMRA SE was added to the resin, and allowed to react for $10 \mathrm{~h}$. Next, the Mtt group on the first lysine residue was removed by a deprotecting reagent (TFA/TIS/DCM $=1: 1: 18$ ). Subsequently, DMF containing three equivalents of chloroacetyl chloride was added to the resin and placed for $6 \mathrm{~h}$. Cleavage from the resin and purification of the compound were conducted following a previous report. ${ }^{6}$ Compound 2 was identified by matrix-assisted laser desorption/ionization time-of-flight (MALDI-TOF) mass spectrometry (Auto-flex III, Bruker Daltonics).

\section{Cell culturing}

Daudi and K562 cells were cultured in RPMI 1640 medium (Wako) containing 20\% (Daudi) or 10\% (K562) fetal bovin serum (FBS), $100 \mathrm{U} / \mathrm{mL}$ penicillin, $100 \mu \mathrm{g} / \mathrm{mL}$ streptomycin, and $0.25 \mu \mathrm{g} / \mathrm{mL}$ amphotericin B (all from Gibco Invitrogen Co., Grand Island, NY). Cells were cultured in a humidified atmosphere containing $5 \% \mathrm{CO}_{2}$ and $95 \%$ air at $37^{\circ} \mathrm{C}$.

\section{Cell staining by 1 or 2}

Daudi cells were washed twice with a serum-free RPMI 1640 medium, and suspended in $50 \mu \mathrm{L}$ of the serum-free medium to a concentration of $4.0 \times 10^{5}$ cells $/ 50 \mu \mathrm{L}$ in a $1.5-\mathrm{mL}$ tube. A substrate solution $(0.2$ or $1 \mu \mathrm{M}$ substrate containing $4 \mathrm{mM}$ $\mathrm{M}-\beta$-CD) was prepared by mixing a DMSO solution of the substrate $(0.4$ or $2 \mu \mathrm{M})$ with a solution of $\mathrm{M}-\beta-\mathrm{CD}(8 \mathrm{mM})$ in the serum-free medium for $30 \mathrm{~min}$. Then, $50 \mu \mathrm{L}$ of the substrate solution was added to the cell suspension, and the cells were incubated at $37^{\circ} \mathrm{C}$ for $2 \mathrm{~h}$. Then, the cells were washed with RPMI 1640 medium containing 10\% FBS. Finally, the cells were resuspended in an appropriate amount of the serum-free medium and analyzed by a BZ-8000 fluorescence microscope (KEYENCE, Japan).

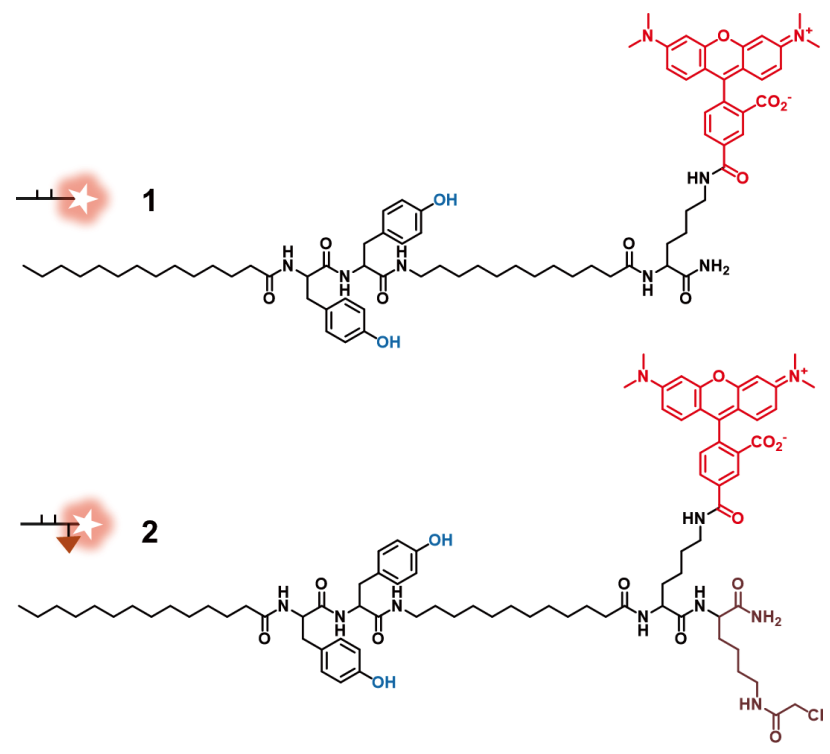

Fig. 2 Chemical structures of fluorescent substrates.

\section{Evaluation of transfer of 1 or $\mathbf{2}$ from stained cells to unstained} cells

K562 cells were washed twice with a serum-free RPMI 1640 medium, and suspended in $50 \mu \mathrm{L}$ of the serum-free medium to a concentration of $4.0 \times 10^{5}$ cells $/ 50 \mu \mathrm{L}$ in a $1.5-\mathrm{mL}$ tube. The cells were stained following the above-mentioned procedures at the final concentration of substrate of $0.5 \mu \mathrm{M}$ and $\mathrm{M}-\beta-\mathrm{CD}$ of $2 \mathrm{mM}$. Then, the cells were washed with a RPMI 1640 medium containing $10 \%$ FBS and suspended in $500 \mu \mathrm{L}$ of the serumfree medium. Then, fresh $\mathrm{K} 562$ cells in $50 \mu \mathrm{L}$ of the serum-free medium $\left(4.0 \times 10^{5}\right.$ cells $\left./ 50 \mu \mathrm{L}\right)$ were mixed with the stained cells and kept at 4 or $37^{\circ} \mathrm{C}$. The fluorescence intensity of the cell mixtures was analyzed by CytoFLEX S (Beckman Coulter).

\section{Results and Discussion}

We designed a chloroacetyl group-modified fluorescent substrate $\mathbf{2}$ based on a substrate $\mathbf{1}$ which was previously found to be a suitable substrate for $\beta$-galactosidase-responsive staining of cells $^{6}$ (Fig. 2). Because of the two hydrophilic galactosyl groups in $\mathbf{1}$, penetration of the cell membrane could be suppressed compared with a substrate with single galactosyl group. ${ }^{6}$ The chloroacetyl group was modified on an $\varepsilon$-amine group of the extra lysine residue. Fluorescent substrates $\mathbf{1}$ and $\mathbf{2}$ are the molecules existing after the enzymatic hydrolysis of $\beta$-galactosyl groups modified on tyrosine residues, which allowed us to evaluate the cell staining behavior of the substrates after hydrolysis.

We stained cells with the fluorescent substrate $\mathbf{1}$ or $\mathbf{2}$ following a procedure we established previously. ${ }^{6}$ A mixture of the substrate and $\mathrm{M}-\beta-\mathrm{CD}$ was added to a cell suspension at $37^{\circ} \mathrm{C}$ for $2 \mathrm{~h}$. The unbound substrate was removed by washing the cells with a serum-containing medium. As shown in Fig. 3, 2 required a higher concentration $(0.5 \mu \mathrm{M})$ to stain the cells with an equivalent intensity to $\mathbf{1}(0.1 \mu \mathrm{M})$. However, an intracellular region stained by $\mathbf{2}$ was similar to $\mathbf{1}$; whole cytosol, except for the nucleus, seemed to be stained. The weaker staining ability of 2 would result from the hydrophilicity of the terminal chloroacetyl lysine residue, which impedes cell membrane permeation of the substrate. 
1

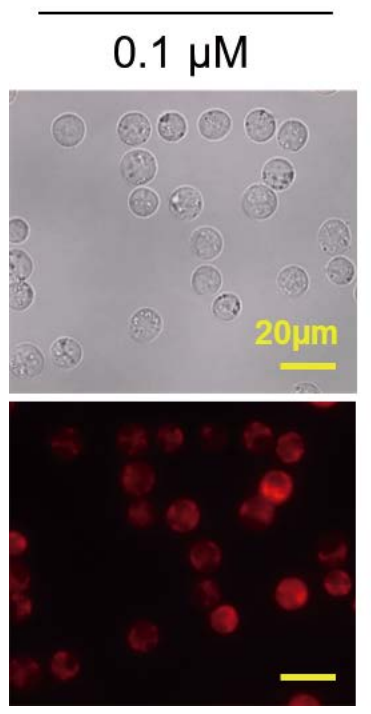

2

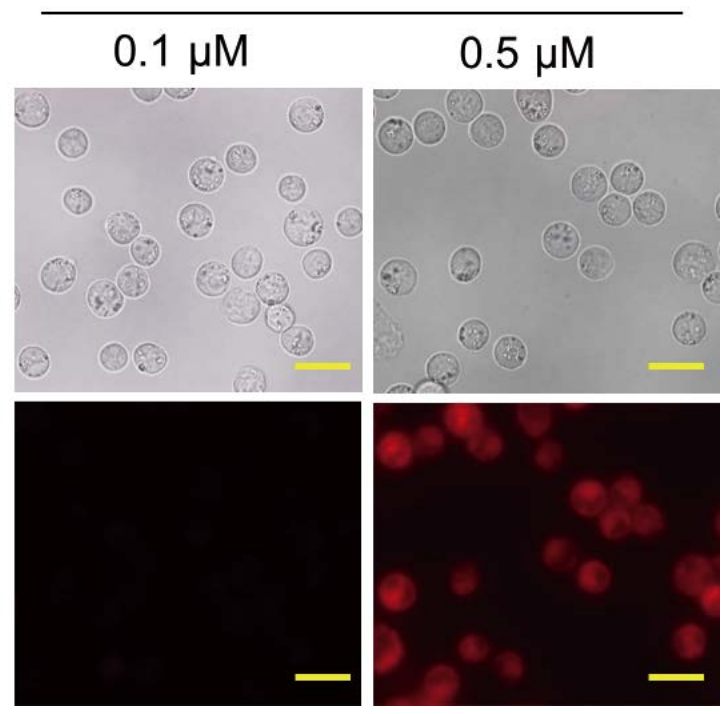

Fig. 3 Microscopic images of Daudi cells stained by fluorescence substrates at indicated concentrations. The upper and lower rows are bright field and fluorescence images, respectively.

1
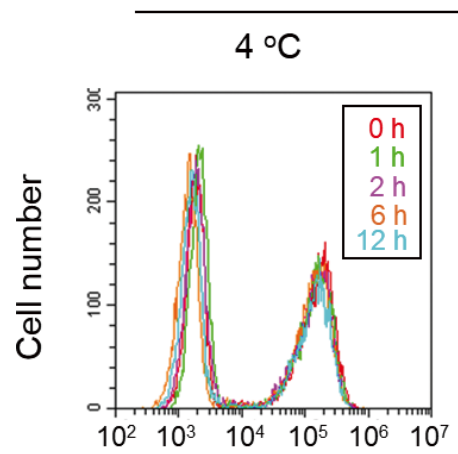

$37^{\circ} \mathrm{C}$

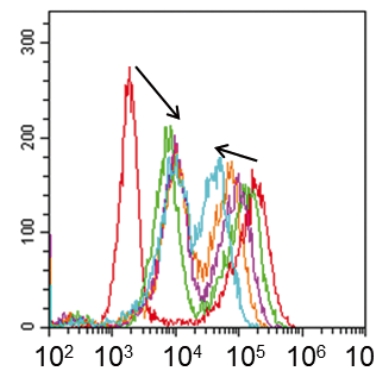

Fluorescence intensity
2

$37^{\circ} \mathrm{C}$

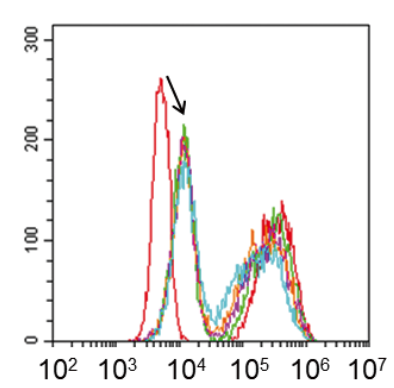

Fig. 4 Evaluation of the transfer of fluorescent substrates from stained to unstained K562 cells at each temperature.

We evaluated the transfer of an substrates $\mathbf{1}$ and $\mathbf{2}$ bound to the cells to unstained cells during the incubation for an extended time. First, the cells were stained by the substrate, and then the stained cells were mixed with the same number of unstained cells. The transfer of the substrates between the stained and unstained cells was evaluated by flow cytometry (Fig. 4). In the case of $\mathbf{1}$, the fluorescence intensities of the stained and the unstained cells were almost constant at $4^{\circ} \mathrm{C}$ during $12 \mathrm{~h}$ incubation, indicating a negligible transfer of substrate $\mathbf{1}$ from the stained cells to the unstained cells. However, at $37^{\circ} \mathrm{C}$, the fluorescence intensity of the stained cells decreased and that of the unstained cells increased with time, showing that substrate $\mathbf{1}$ transferred from the stained cells to the unstained cells. Suppression of the transfer of $\mathbf{1}$ at $4^{\circ} \mathrm{C}$ indicates that the transfer includes an energy-dependent process. Transporters expressed on the cell membrane that pumps out hydrophobic molecules from cytosol to the outer medium may be responsible for the dissociation process of the substrate from the stained cells. ${ }^{11}$
Another possible energy-dependent process to release the substrate from the stained cells would be an exosome-mediated release..$^{12,13}$

In the case of 2 at $37^{\circ} \mathrm{C}$, the fluorescence increase of the unstained cells was observed in the first one hour, and then the increment was suppressed later. The cells stained by $\mathbf{2}$ showed a minor reduction in the fluorescence compared with those stained by $\mathbf{1}$. These results indicated that fraction of $\mathbf{2}$ which did not form the covalent bond with intracellular proteins dissociated from the stained cells in the first one hour, while the fraction of $\mathbf{2}$ that bound covalently did not dissociate any more.

Thus, the covalent bond formation of $\mathbf{2}$ with intracellular proteins is advantageous to suppress a transfer of the substrate to the unstained cells. However, because of a mild reactivity of the chloroacetyl group, some time was required for the covalent bond formation. As a solution to this issue, we recently reported a fluorescent substrate that acquires a quite high reactivity upon enzymatic hydrolysis. ${ }^{14}$ 


\section{Conclusions}

We designed a fluorescent substrate $\mathbf{2}$ with a chloroacetyl group to suppress any transfer of the substrate to unstained cells. The substrate achieved to suppress dissociation from the stained cells, leading to a reduction in the transfer to the unstained cells. However, the slow reaction speed of $\mathbf{2}$ with intracellular proteins allowed for dissociation in the early stage of the staining reaction.

\section{Acknowledgements}

This work was supported by Grant-in-Aid for Scientific Research B (project No. 16H04167) and A (project No. 18H03936) of MEXT, Japan.

\section{References}

1. W. R. Zipfel, R. M. Williams, R. Christiet, A. Y. Nikitin, B. T. Hyman, and W. W. Webb, Proc. Natl. Acad. Sci. U. S. A., 2003, 100, 7075 .

2. A. Schwartz, G. E. Marti, R. Poon, J. W. Gratama, and E. Fernández-Repollet, Cytometry, 1998, 33, 106.

3. A. P. Acharya, P. M. Nafisi, A. Gardner, J. L. MacKay, K. Kundu, S. Kumar, and N. Murthy, Chem. Commun., 2013 , 49, 10379.

4. M. N. Bobrow, K. J. Shaughnessy, and G. J. Litt, J.
Immunol. Methods, 1991, 137, 103.

5. M. R. Clutter, G. C. Heffner, P. O. Krutzik, K. L. Sachen, and G. P. Nolan, Cytom. Part A, 2010, 77, 1020.

6. T. Nobori, M. Kawamura, R. Yoshida, T. Joichi, K. Kamino, A. Kishimura, E. Baba, T. Mori, and Y. Katayama, Anal. Chem., 2020, 92, 3069.

7. T. Nobori, K. Tosaka, A. Kawamura, T. Joichi, K. Kamino, A. Kishimura, E. Baba, T. Mori, and Y. Katayama, Anal. Chem., 2018, 90, 1059.

8. T. Hiratsuka, J. Biol. Chem., 1993, 268, 24742.

9. S. P. Perfetto, P. K. Chattopadhyay, L. Lamoreaux, R. Nguyen, D. Ambrozak, R. A. Koup, and M. Roederer, Curr. Protoc. Cytom., 2010, 1.

10. K. M. Backus, B. E. Correia, K. M. Lum, S. Forli, B. D. Horning, G. E. González-Páez, S. Chatterjee, B. R. Lanning, J. R. Teijaro, A. J. Olson, D. W. Wolan, and B. F. Cravatt, Nature, 2016, 534, 570.

11. K. Inui, S. Masuda, and H. Saito, Kidney Int., 2000, 58, 944.

12. D. K. Jeppesen, A. M. Fenix, J. L. Franklin, J. N. Higginbotham, Q. Zhang, L. J. Zimmerman, D. C. Liebler, J. Ping, Q. Liu, R. Evans, W. H. Fissell, J. G. Patton, L. H. Rome, D. T. Burnette, and R. J. Coffey, Cell, 2019, 177, 428.

13. J. Gertner-Dardenne, M. Poupot, B. Gray, and J. J. Fournié, Immunol. Invest., 2007, 36, 665.

14. K. Noguchi, T. Shimomura, Y. Ohuchi, M. Ishiyama, M. Shiga, T. Mori, Y. Katayama, and Y. Ueno, Bioconjugate Chem., 2020, 31, 1740. 